\title{
Paraguay: una propuesta de financiamiento de viviendas para los segmentos de ingresos medios-bajos
}

\author{
J. Vicente Fruet Cardozo y Guzmán A. Muñoz Fernández
}

RESUMEN

La construcción y la propiedad de viviendas son fundamentales para el desarrollo económico, la creación de riqueza y la formación de la clase media. Pese a los numerosos estudios y programas implementados en décadas recientes, persiste un marcado déficit de viviendas en el Paraguay, así como en América Latina, porque estos programas no han sido exitosos. El mayor obstáculo para las familias al intentar adquirir una vivienda y no poder acreditar ingresos regulares, suele ser el financiamiento. En este trabajo se procura demostrar la factibilidad económica y financiera — siempre que exista voluntad política y coordinación entre entidades privadas y públicas- de un proyecto de construcción de 75.000 viviendas para 300.000 personas (el 4,5\% de la población paraguaya) con ingresos medios-bajos. Este segmento poblacional, con grave carencia de viviendas decentes, tiene un ingreso medio de 396,5 dólares por hogar, pudiendo destinar hasta 63,44 dólares mensuales a costos relacionados con la vivienda.

PALABRAS CLAVE

CLASIFICACIÓN JEL

AUTORES
Vivienda, necesidades de vivienda, financiación de la vivienda, igualdad, familia, ingresos, política de vivienda, Paraguay

O18, G21, R31

J. Vicente Fruet Cardozo es Profesor de la Universidad de Córdoba, Departamento de Economía, Sociología y Política Agraria, España. es1frcaj@uco.es

Guzmán A. Muñoz Fernández es Profesor de la Universidad de Córdoba, Departamento de Estadística, Econometría, Investigación Operativa, Organización de Empresas y Economía Aplicada, España. guzman.munoz@uco.es 


\section{I}

\section{Introducción}

La vivienda es el bien más importante de una familia y una de las necesidades básicas del ser humano, tan esencial como disponer de alimento y de un medio de subsistencia, y se considera uno de los indicadores clave para determinar la situación económica de un país. Probablemente es uno de los sectores sociales a los que más apuntan los legisladores y los responsables de las políticas públicas, quienes actúan sobre la base de que la vivienda es un derecho fundamental consagrado en la legislación de los países más avanzados. En la Constitución del Paraguay se recoge este derecho en tres artículos diferentes, en los que se dispone que el "Estado establecerá las condiciones para hacer efectivo este derecho y promoverá planes de vivienda de interés social, especialmente la destinada a familias de escasos recursos, mediante sistemas de financiamiento adecuados". Si este derecho figura en la ley fundamental del país y en otras leyes de menor rango, ¿por qué sigue habiendo un gran número de ciudadanos que viven en condiciones inadecuadas? "En algunos casos las familias no pueden costearse ni siquiera una vivienda básica. En otros casos, $\mathrm{y}$ aunque ganen lo suficiente para adquirir algo mejor, no logran conseguir una hipoteca al no poder documentar sus ingresos porque los mercados de crédito son muy poco profundos o porque el crédito hipotecario es demasiado costoso. En otras ocasiones no hay viviendas disponibles que puedan comprar" (Bouillon, 2012, pág. 21).

Los principales desafíos que se debe plantear el sector de la vivienda en el Paraguay son la eliminación de estas carencias cuantitativas y cualitativas y la necesidad de edificar más viviendas. Según el Fondo Nacional de la Vivienda Social (FONAVIS), históricamente, la mayoría de los programas de vivienda implementados por el Instituto Paraguayo de Vivienda y Urbanismo (IPVU), el Banco Nacional de la Vivienda y el Consejo Nacional de la Vivienda (CONAVI) se han desviado hacia estratos con capacidad de pago y, en consecuencia, las familias sin o con pocos ingresos solo reciben asistencia de manera esporádica ${ }^{1}$. De ahí que la mayoría de estas últimas intervenciones hayan resultado fracasadas, debido a los compromisos impagos surgidos al poco tiempo y las consecuentes moras, que se han traducido en graves

\footnotetext{
${ }^{1}$ Fondo Nacional de la Vivienda Social (FONAVIS), Secretaría Nacional de la Vivienda y el Hábitat (SEnavitat, 2010).
}

problemas sociales. Todo esto obedece principalmente al abandono, la corrupción o ambos de la administración que, como respuesta a la falta de confianza originada por la malversación de recursos financieros, resolvió no asignar fondos o no utilizar plenamente los recursos presupuestados $^{2}$. Otro problema importante es la falta de sostenibilidad de los programas de vivienda, ya sean financiados por el gobierno, organizaciones no gubernamentales (ONG) o entidades extranjeras.

El 59,53\% de la población de la República del Paraguay es urbana y el $43 \%$ reside en el área metropolitana de Asunción, que se compone de 20 municipalidades (Páez, 2011). La mayoría de las personas residen en casas (el 83,92\%) y menos frecuentemente en ranchos (el 11,54\%), según la Dirección General de Estadística, Encuestas y Censos. Estos dos tipos de vivienda representan el 95,46\% del total del parque inmobiliario. La hegemonía de estas edificaciones ha disminuido lentamente en los últimos 30 años. Su prevalencia sugiere que, dadas las posibilidades que ofrece el espacio físico existente en el Paraguay, la urbanización del territorio ha sido horizontal en lugar de vertical. Asimismo, también se caracteriza por la presencia consolidada de un gran número de barrios periféricos en crecimiento que no se encuentran completamente edificados, sino que presentan múltiples parcelas vacías entre aquellas construidas. Esta situación se da también en áreas urbanas no céntricas.

En este artículo se formula un plan de financiamiento para ofrecer una solución de vivienda a 300.000 ciudadanos paraguayos. Se dirige específicamente a las familias con ingresos bajos o medios-bajos sin acceso a ningún tipo de financiamiento en el mercado de la vivienda. Sin duda, este tipo de proyectos a gran escala puede servir de motor económico para impulsar el consumo interno del país, además de ofrecer financiamiento a nuevas actividades económicas y garantías hipotecarias para una buena parte de la población. Esta propuesta no se basa en la construcción de urbanizaciones siguiendo el modelo occidental, en el que el promotor construye las

\footnotetext{
${ }^{2}$ Según datos del Sistema Integrado de Programación Presupuestaria (SIPP), el Sistema Integrado de Contabilidad (SICO) y el Sistema Integrado de Administración Financiera (SIAF), de un presupuesto de 616.000 millones de guaraníes (135,52 millones de dólares) en 2012, la ejecución real solo incluyó un $63,9 \%$.
} 
casas, la infraestructura y los nuevos servicios, lo que afecta al precio de la vivienda y exige una gran inversión inicial, sino que con ella se fomentaría la construcción por parte del propietario o de pequeñas constructoras, a fin de aprovechar las pequeñas parcelas que un gran número de familias paraguayas ya poseen. Estas familias cuentan con ingresos medios-bajos que no bastan para financiar la construcción de una vivienda digna, de modo que la propuesta descrita se centraría principalmente en lo que el reglamento de programas habitacionales de FONAVIS llama "edificación en lote propio".

Para que el proyecto se desenvuelva con éxito, las autoridades deben intervenir en dos aspectos: en primer lugar, desde el punto de vista técnico, el diseño tiene que cumplir los requisitos técnicos y estructurales mínimos de FONAVIS y se debe avanzar en el desarrollo de obras civiles en el distrito; en segundo lugar, la construcción debe financiarse a través de pagos periódicos por unidades de obra construidas y verificadas. El objetivo sería una licitación anual de 7.500 viviendas con dimensiones de hasta $60 \mathrm{~m}^{2}$, que se llevaría a cabo de forma anual, si bien lógicamente tendría un proceso más largo de finalización, con un pago final una vez completado el proyecto.

Este artículo se focaliza en el análisis de la viabilidad financiera necesaria para cumplir este objetivo. Luego de esta Introducción, en la sección II se revisan las anteriores publicaciones en materia económica sobre el financiamiento de la vivienda. En la sección III se determina el déficit de vivienda en el Paraguay, con el propósito de definir el sector de población estudiado en este trabajo. A continuación, en la sección IV, se da a conocer el plan de financiamiento y amortización propuesto para la construcción de viviendas y los operadores económicos que habrían de participar. Por último, en la sección $\mathrm{V}$ se presentan conclusiones y recomendaciones en materia de política de vivienda.

\section{II}

\section{Análisis bibliográfico en materia de financiamiento de vivienda}

En las publicaciones económicas clásicas, los ingresos de los hogares aparecen como uno de los factores principales que determinan la demanda de vivienda (Morton, 1955; Friedman, 1957; De Leeuw, 1971; Poterba, 1984, entre otros). Según la interpretación práctica de la obra de Muth (1969) y su teoría del ingreso permanente del mercado de la vivienda, el consumo de servicios habitacionales de cada familia se ve limitado por su presupuesto. Si las familias cuentan con ingresos asegurados y continuos durante un largo período de tiempo, basarán sus decisiones de gasto e inversión en bienes duraderos, como la compra de una casa, lo que favorece la demanda de viviendas regulares. No obstante, en primer lugar se debe distinguir entre la capacidad de compra y la capacidad de pago. La primera se refiere a la conexión que existe entre el precio de las viviendas y el salario medio, que depende de los ingresos disponibles de cada familia, estrechamente relacionados con los ingresos habituales del hogar y con la estabilidad del empleo. La capacidad de pago se refiere a la presión que ejerce el desembolso de pagos sobre los ingresos disponibles y depende de los siguientes factores de los créditos hipotecarios: disponibilidad de financiamiento, tasa de financiamiento según la tasación de la vivienda y disposición de los promotores inmobiliarios y las entidades a cargo de las condiciones para el reembolso y los atrasos, que serán quienes decidan el valor que debe pagar cada familia. También son fundamentales el acceso a préstamos, sus condiciones y la forma en que se subvencionan estos recursos (Fallis y Smith, 1984; Muellbauer y Murphy, 1997; Young, 2007).

En cualquier caso, los préstamos hipotecarios suelen requerir pagos mensuales a largo plazo, un crédito demostrable y una fuente de ingresos estable y verificable; es decir, un puesto remunerado en el sector formal. Muchos hogares de países en desarrollo cuentan con ingresos bajos o moderados, que son fluctuantes y provienen del sector informal. Además, muy pocos tienen algún tipo de historial de crédito y es común que posean títulos de propiedad de dudosa legitimidad. Así, los derechos patrimoniales y la capacidad de recuperación tras la ejecución hipotecaria son algunos de los principales problemas del financiamiento hipotecario tradicional. A las instituciones financieras privadas, por lo tanto, no les interesa expandir sus planes de financiamiento hipotecario a este mercado (Daphnis, 2006). Otro impedimento importante para el desarrollo del mercado hipotecario de América Latina ha sido la excesiva tendencia de las 
instituciones a "no cobrar", debido a la ausencia de criterios claros sobre la recuperación económica en las políticas de vivienda de varios organismos. En la mayoría de los casos, debido a motivaciones políticas populistas, esto ha conducido a la consolidación de la cultura de "no pagar" (Connolly, 1997).

La propiedad de la vivienda es fundamental para el desarrollo económico de un país y es especialmente importante para la creación de riqueza en los hogares y la formación de la clase media (Ferguson y Navarrete, 2003). De Soto (2000) se refiere a las implicaciones de las instituciones de derechos patrimoniales en el desarrollo económico. Su hipótesis consiste en que la seguridad de los derechos patrimoniales favorece la acumulación de capital a largo plazo y el acceso al crédito, lo que conduce al crecimiento económico. Bauer (2000) también argumenta que la formación de capital es esencial para que la economía progrese desde una producción de subsistencia a una producción de mercado. Otros autores establecen vínculos teóricos entre la seguridad de los derechos patrimoniales y el desarrollo económico (Acemoglu, Johnson y Robinson, 2002; Kerekes y Williamson, 2008). Por otra parte, un marco adecuado de derechos patrimoniales podría ayudar a fortalecer el sistema financiero, dado que es la forma más segura de emitir deuda privada y de que los préstamos hipotecarios presenten un riesgo bajo. Además, los derechos patrimoniales representan más de un tercio de los activos de las instituciones financieras en los países desarrollados. En contraste, en los países en desarrollo hay una escasez de activos inmobiliarios, lo que repercute negativamente en su sistema financiero. De esta forma, al no poder invertir en préstamos hipotecarios, los bancos deben gastar gran parte de sus fondos en proyectos de mayor riesgo. La vivienda no es solo un techo: también es un producto que ofrece seguridad social, porque el espacio puede aprovecharse para llevar a cabo actividades generadoras de ingresos, como un comercio o un taller, y combinar las funciones de vivienda y de producción, además de ser una garantía en caso de necesidad económica (Smets, 2006). Asimismo, este crecimiento en el mercado nacional contribuye a crear una alternativa para las economías que dependen de las exportaciones (Ferguson, 2006), especialmente de las materias primas.

A diferencia de los países desarrollados, donde una vivienda simplemente se arrienda o se compra, en la mayoría de las naciones en desarrollo existe un mercado inmobiliario informal que incluye proyectos irregulares de construcción de la propia casa (en un terreno en propiedad o en uno ocupado de manera ilegal), viviendas divididas por subarriendos o incluso compartidas (Coccato, 1996). La razón principal por la que las familias no pueden permitirse una vivienda formal es la falta de ingresos. En América Latina, esto se suma a un funcionamiento deficiente de los mercados financieros, la dificultad de presentar información fiable con respecto a los ingresos y la ajustada oferta de vivienda social por parte del sector privado.

Sin financiamiento, las familias de escasos recursos solo pueden adquirir cantidades reducidas de material de construcción y edificar viviendas de calidad inferior. Este sería uno de los casos en que resultaría beneficioso utilizar microcréditos para favorecer el desarrollo social y luchar contra la pobreza. La situación de los hogares mejoraría al incrementarse los ingresos con sumas de entre 500 dólares y 2.000 dólares (Ferguson y Smets, 2010, pág. 290) provenientes de estos pequeños préstamos a corto plazo con intereses no subvencionados (Serageldin y Driscoll, 2000) para comprar materiales de construcción y así ampliar y reformar la propia vivienda y mejorar las condiciones de vida (vivienda progresiva). Estos créditos, canalizados a través de ONG, se basan más en la supervisión constante que en la existencia de garantías reales. En realidad, el objetivo de este tipo de financiamiento es que los recursos económicos destinados a la vivienda se utilicen en el sector informal de la construcción de la propia vivienda (González Arrieta, 2005, pág. 128).

Sin embargo, entre las nuevas iniciativas propuestas en los países en desarrollo con relación a la vivienda, algunas publicaciones sugieren que los microcréditos se utilicen no solo para mejorar los hogares, sino también para construir nuevas unidades básicas de vivienda. Según Hammond y otros, existe un gran volumen de peticiones de préstamo de entre 2.500 dólares y 10.000 dólares, cantidades que corresponden a las familias de clase baja y media que tampoco tienen acceso a servicios de financiamiento. Este es un gran mercado potencial que podría generar hasta 331.800 millones de dólares a nivel mundial. Las instituciones tradicionales de financiamiento hipotecario no han creado mecanismos para dar servicio a estos mercados, y los órganos institucionales tampoco ofrecen microcréditos o mayores préstamos para adquirir o reformar viviendas. Con miras a satisfacer esta demanda sería necesario un crédito más largo, de entre 10 y 30 años, con una tasa de interés menor, nuevos métodos (de financiamiento, aseguramiento, tramitación, concesión y cobro de los préstamos y de gestión del riesgo) e innovación institucional (Ferguson y Smets, 2010). De este modo, es necesario crear una amplia gama de productos de crédito innovadores para satisfacer las necesidades de vivienda de países en desarrollo como el Paraguay. 


\section{III}

\section{El sector de la vivienda}

Según el informe anual de 2012 de la Secretaría Nacional de la Vivienda y el Hábitat (SENAVITAT) y la Dirección General de Estadísticas, Encuestas y Censos (DGEEyc), a fecha del 31 de diciembre de ese año, el Paraguay presentaba un déficit habitacional de 1,2 millones de viviendas. Esta cifra se puede desglosar en: 150.000 viviendas que habría que construir, 300.000 que requieren grandes reformas (estas dos últimas categorías podrían considerarse como problemas urgentes), 320.000 que necesitan una ampliación y 430.000 que no constituyen una prioridad. El Paraguay tiene una población de 6.600 .000 habitantes y un total de 1.652 .895 viviendas, es decir, que en cada hogar reside una media de cuatro personas. Esto significa que unos 3,08 millones de personas (el 46,7\% de la población total) tienen problemas urgentes de vivienda. La propuesta que se expone en este artículo se centra en torno de la construcción de 75.000 viviendas a lo largo de un período de 10 años (la mitad del déficit de la sección "Por construir" del gráfico 1). Esto representa un público beneficiario de 300.000 personas, de las 377.244 mencionadas en la línea 5 del cuadro 1. Estas familias deben poseer tierras por un

\section{GRÁFICO 1}

Paraguay: distribución del déficit de la vivienda, 2012

(Número de viviendas)

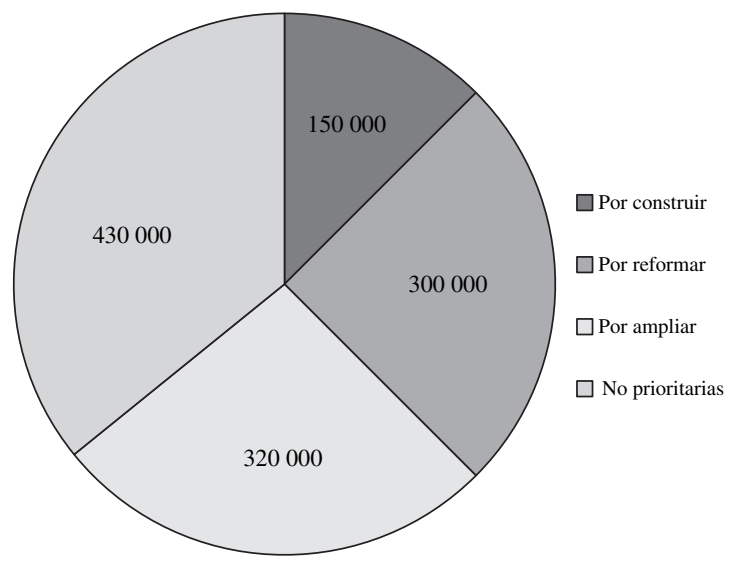

Fuente: Elaboración propia, sobre la base de información de la Dirección General de Estadísticas, Encuestas y Censos (DGEEC), Encuesta Permanente de Hogares (EPH), 2012 [en línea] http:// www.dgeec.gov.py/Publicaciones/Biblioteca/EPH2012/principales_ resultados_EPH2012.pdf. valor equivalente a 1.600 dólares, que constituirán la contribución de contraparte.

El costo unitario de este tipo de vivienda se estima en 8.000 dólares. Este es el precio de cada una de las 38 viviendas sociales que la SENAVITAT entregó a sus nuevos propietarios en julio de 2012. Por lo tanto, el total de la inversión que sería necesaria para resolver este problema social se situaría en torno de los 9.600 millones de dólares. Sin lugar a dudas, una suma excesiva para la frágil economía paraguaya.

El gobierno cumple una función muy limitada en este sector. El Estado gestiona algunos programas de vivienda social y construye unas 5.000 viviendas anuales, pero la demanda es 15 o 20 veces mayor, según declaró Francisco Knapps, antiguo presidente de SENAVITAT, en octubre de 2013 tras haberse reunido con el recién elegido presidente del país, Horacio Cartes. Por lo tanto, así solo se define un marco razonable que regula los parámetros de lo que constituiría un proyecto de vivienda aceptable, y los lugares en los que se podría edificar. Con relación a esta cuestión, las cifras oficiales confirman que el 96,92\% de la construcción de viviendas en el Paraguay entre 1950 y el 31 de diciembre de 2010 fue realizada por el sector privado.

Por esta misma razón, de más está señalar que si el Gobierno del Paraguay no participa junto al sector privado en la construcción de vivienda, el mercado nunca será capaz de ofrecer una solución real a esta alarmante situación. Al respecto, la participación del gobierno debería realizarse en tres ámbitos: la definición previa de una política de vivienda en el Paraguay; la participación de la Agencia Financiera de Desarrollo $(\mathrm{AFD})^{3}$, en coordinación con la SENAVITAT, que constituye el principal organismo del sector de la vivienda en el Paraguay, y la obtención de recursos económicos accesibles para financiar un programa de construcción destinado a este gran número de personas.

\footnotetext{
${ }^{3}$ El 27 de julio de 2005, fecha en que se promulgó la Ley 2640, se creó la Agencia Financiera de Desarrollo (AFD) como único banco público de segundo piso. Ha reemplazado en todas sus funciones a varias secciones del banco público, entre ellas al Banco Nacional de Ahorro y Préstamo para la Vivienda (BNAPV).
} 


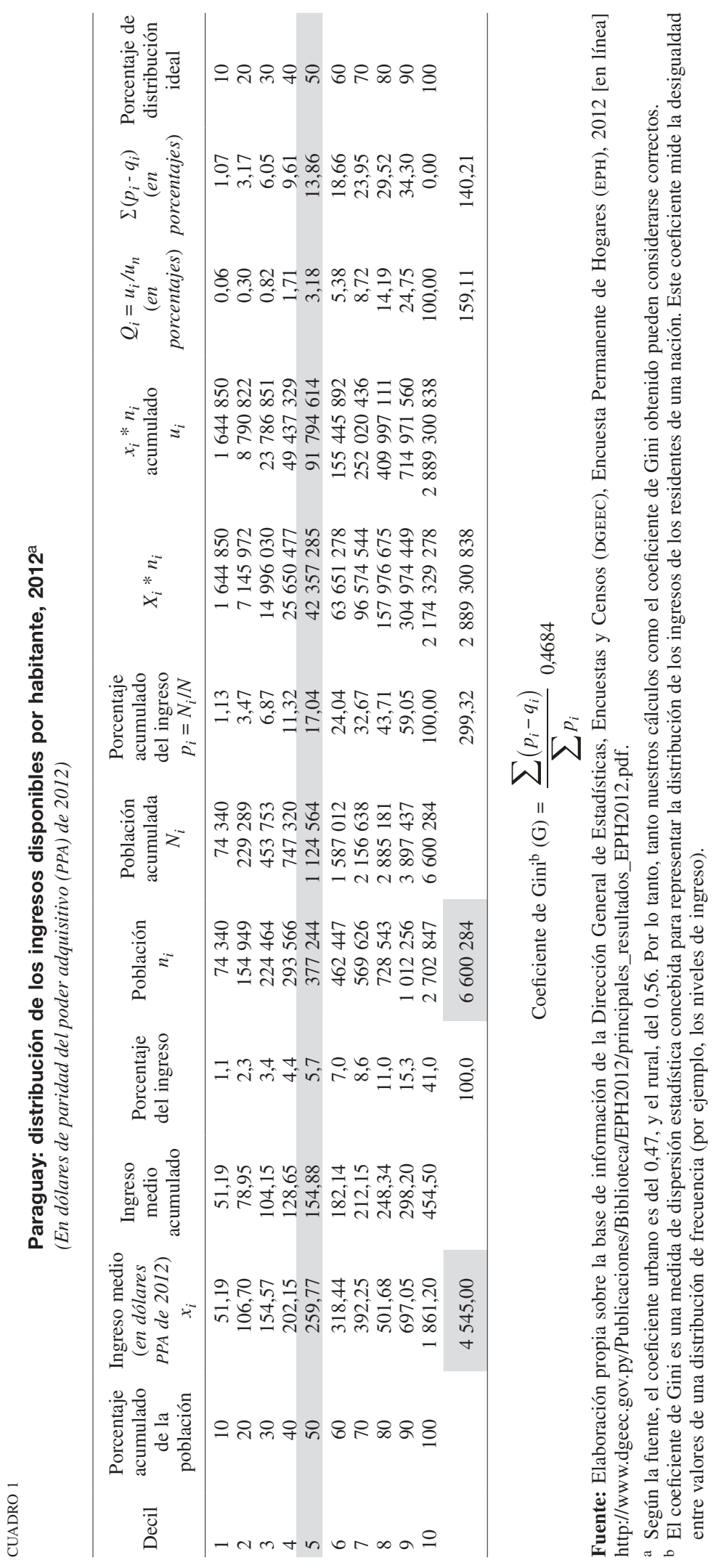




\section{El déficit de la vivienda y la población afectada}

El presente estudio está dirigido a un segmento específico que se sitúa por debajo de la línea 5 del cuadro 1, en el que se muestra la distribución de los ingresos disponibles por habitante en 2012 (DGEEC, 2012). El resultado del cuadro conduce a la llamada curva de Lorenz, que es una representación gráfica de la función de distribución acumulativa de la distribución de probabilidad de riqueza empírica. Se ha clasificado a la población pobre del Paraguay en cinco niveles, según la distribución de los ingresos disponibles por habitante. La renta per cápita del Paraguay, medida en dólares de paridad de poder adquisitivo (PPA) ${ }^{4}$, es de 4.545 dólares. Se ha desglosado en deciles, con el valor de los dólares PPA de 2012.

\section{Clasificación de la población afectada}

El grupo de población mostrado en la línea 5 del cuadro 1 , al que se ha denominado "de ingresos medios-bajos", representa a familias de clase media que reciben el salario mínimo (en torno a los 396,5 dólares al mes). Estas familias carecen de acceso a financiamiento por parte del sistema bancario debido a los altos costos de las

${ }^{4}$ El dólar de paridad de poder adquisitivo (PPA) es la unidad de medida económica que permite estandarizar la paridad del poder adquisitivo de los ingresos disponibles por habitante en los diferentes países del mundo. líneas de crédito hipotecarias actuales. Para simplificar los cálculos, se ha redondeado el número de 377.244 a 300.000 personas, que necesitan unas 75.000 viviendas.

\section{3. ¿Qué pasa con los otros cuatro deciles?}

Los otros cuatro grupos que se observan en las líneas 1 a 4 , a los que se ha denominado "de ingresos muy bajos", representan cerca de un $11,32 \%$ de la población total: unas 747.320 personas que subsisten en las zonas pobres de la periferia de las ciudades y forman parte de la población que vive por debajo del umbral de la pobreza 5 . Estas personas ni siquiera pueden pagar los 2 dólares que se necesitan para comprar comida suficiente cada día. Debido a sus bajos niveles de ingresos, no tienen capacidad de endeudamiento para pedir una hipoteca, por lo que desgraciadamente no se presenta en este estudio ninguna alternativa posible de financiamiento para las 186.830 viviendas que estos grupos necesitan; ya que resulta imposible diseñar un programa de hipotecas viable para este segmento de la población. Generalmente, los programas de vivienda para estos grupos están supeditados a los recursos financieros de instituciones extranjeras o de organizaciones benéficas internacionales.

\footnotetext{
5 Véase PNUD (2010). Según este informe, el 29,8\% de la población
} del Paraguay vive por debajo del umbral de la pobreza.

\section{IV}

\section{Alternativas de financiamiento para el sector de la vivienda}

\section{Alternativa de financiamiento para el grupo de ingresos medios-bajos}

\section{a) Conceptos generales}

Se ha elaborado un proyecto de financiamiento de viviendas para este grupo basado en una línea de crédito de 20 años de duración, con las condiciones adecuadas para los ingresos disponibles por habitante y con un período de gracia de 4 años. El proyecto se llevaría a cabo a través de la Agencia Financiera de Desarrollo (AFD), en calidad de institución de segundo piso ${ }^{6}$. Participarían además 12 instituciones financieras intermediarias (IFI) de primer piso: 11 cooperativas de préstamo (Lambaré, Mburicaó, Medalla Milagrosa, Copacons, Coomecipar, Universitaria, Educadores, San Juan Bautista, Ayacapé, Ypacaraí y Fuerzas Armadas de la Nación) que ya están

\footnotetext{
${ }^{6}$ Las instituciones financieras de segundo piso no conceden créditos de forma directa a los prestatarios, sino a través de instituciones de primer piso, como bancos comerciales, bancos hipotecarios, asociaciones de ahorro y préstamo o cooperativas de préstamo.
} 
presentes en programas de la AFD y una sociedad de ahorro y préstamo (Solar de Ahorro y Préstamo para la Vivienda). No se ha considerado a los bancos comerciales por dos motivos: en primer lugar, porque las personas de clase media-baja no acuden a este tipo de instituciones $y$, en segundo lugar, porque los bancos comerciales participarán en el mercado secundario de este proyecto.

b) Cuadro de la amortización de los préstamos concedidos por la AFD a las entidades de primer piso

En el cuadro 2 se detalla el financiamiento concedido por la AFD a las entidades de primer piso. Cabe notar que en la política de la AFD para financiar vivienda social se estipula el uso de tasas de interés fijas hasta un máximo de 20 años. La entidad recomienda de forma específica aplicar una tasa de interés del 5,5\% anual para los préstamos a beneficiarios que ganan hasta cinco veces el salario mínimo. Las IFI pueden añadir a este porcentaje una tasa de interés máxima del $4 \%$, lo que sumado al $5,5 \%$ equivale a una tasa de interés máxima anual del $9,5 \%$. Como se puede observar, el resultado es una tasa de interés anual efectiva del 7,25\%.

\section{c) Cuadro de la amortización de la hipoteca de cada familia \\ A continuación se presenta el cuadro de la hipoteca} para familias de ingresos medios-bajos formadas por cuatro personas. En este caso se presume que una sola persona paga la hipoteca, lo cual es un aspecto positivo para el proyecto, porque normalmente en una familia de ingresos medios-bajos suele trabajar más de una persona. Además, como se menciona en la sección III, los beneficiarios del programa deben ser propietarios de tierras con un valor en torno a los 1.600 dólares que constituirán la contribución de contraparte. Los ingresos medios de estos hogares corresponden al salario mínimo de 396,5 dólares. Se estima que de este nivel de ingresos se puede asignar el $16 \%$ al pago de una vivienda mínimamente digna: unos 63,44 dólares mensuales, 761,28 dólares anuales. Los beneficiarios pueden utilizar hasta el $16 \%$ del salario mínimo para saldar su hipoteca. Este porcentaje representa el costo mensual de la canasta básica de alimentos para una persona. Dado que la familia media se compone de cuatro miembros, todos ellos habrían de subsistir con la canasta básica de alimentos de tres personas, pero a cambio tendrían la posibilidad de ser propietarios de una vivienda. El proyecto no sería factible si estos hogares tuvieran que pagar más del 16\% (DGEEC, 2011a). Las cifras restantes están representadas en el cuadro 3 .

En el cuadro del anexo 1 se expone la amortización del préstamo por cada familia. La última columna muestra la suma total que deben pagar anualmente las familias de ingresos medios-bajos. Nótese que entre el quinto y el décimo año, la cantidad anual que deben pagar los hogares excede ligeramente su capacidad de pago, fijada en 761,28 dólares. No obstante, esta situación debería resolverse por sí misma con el aumento anual del salario mínimo.

CUADRO 2

Paraguay: datos generales de los préstamos concedidos por la AFD a las entidades de primer piso

Número de viviendas

Costo individual de cada vivienda

Inversión total del proyecto

Financiamiento total de la AFD por medio de entidades de primer piso Inversión anual del proyecto

Financiamiento anual de la AFD por medio de entidades de primer piso

Plazo de amortización del préstamo

Contraparte de los beneficiarios

Tasa de interés fija

Tasa de interés efectiva

Período de gracia

Modalidad de pago

Años de duración de la construcción de las viviendas

Porcentaje de costos generales y administrativos
75000

8000 dólares 600000000 dólares 480000000 dólares 60000000 dólares $80 \%$ $20 \%$ 48000000 dólares 20 años

12000000 dólares $5,5 \%$ $7,25 \%$ 4 años Trimestral 10 $5 \%$ sobre intereses

Fuente: Elaboración propia. 
Número de viviendas

Costo individual de cada vivienda

Financiamiento de la AFD por medio de entidades de primer piso

Contribución de los beneficiarios

Plazo para el reembolso

Total de los intereses

Tasa de interés fija del préstamo concedido por la entidad de primer piso $^{\mathrm{a}}$

Tasa de interés efectiva

Gastos generales y administrativos

Período de gracia para el reembolso del principal

Modalidad de pago

Duración de la construcción de las viviendas

Fuente: Elaboración propia.

a En el caso de proyectos sociales cuyos beneficiarios son personas de ingresos medios-bajos, se recomienda el uso de tasas de interés fijas. La AFD otorga préstamos a las instituciones financieras de primer piso a una tasa del 5,5\%, y estas, a su vez, otorgan sus préstamos a los beneficiarios a una tasa del $10 \%$.

b Cobrado sobre los intereses recibidos.

\section{d) Flujos de caja del proyecto de financiamiento de vivienda}

El flujo de caja de un proyecto es un estado financiero y económico que sintetiza el análisis de costos y beneficios realizado previamente. El objetivo principal es demostrar la viabilidad del proyecto, lo que significa que cualquier flujo que se añada posteriormente con una tasa de descuento debe superar la inversión inicial. El mejor componente para definir la viabilidad es el valor actual neto (VAN). Cuando se realiza este tipo de proyectos empresariales en el sector privado la cuestión es más simple: el van ha de ser positivo y la persona que hace el negocio debe encontrarse satisfecha. En los proyectos sociales, como se menciona más adelante, la cuestión se torna más compleja. Otro componente de este análisis es la tasa interna de rentabilidad (TIR). Esta es menos relevante que el vAN, pero determina el umbral de rentabilidad del proyecto.

Con relación a los flujos de caja, se deben considerar los siguientes aspectos:

- El perfil del proyecto se ha trazado desde el punto de vista de la AFD.

- El período de construcción de las viviendas es de 10 años, entre el año 0 y el año 9 . Se construirán un número estimado de 7.500 viviendas al año.

- Durante estos diez años, la AFD - a través de las entidades de primer piso mencionadas anteriormente- facilitará hipotecas para la construcción en diez entregas de igual cuantía. Estas representan las inversiones iniciales del proyecto.

- Si bien el cuadro de amortización de los préstamos cubre un plazo de 20 años, el ciclo vital del proyecto es de 29 años. Esto se debe a que, llegado el año 9, en el que se emiten los préstamos para la construcción del último grupo de 7.500 viviendas, comienza un período de gracia de cuatro años para la amortización del principal. Por lo tanto, la devolución del capital para los préstamos concedidos en el año 9 empieza en el año 13, y a partir de ese año, se deben añadir 16 años más para el reintegro de los préstamos. Por este motivo, dicha devolución finaliza en el año 28.

- La inversión inicial se calcula multiplicando la cantidad de cada préstamo (6.400 dólares) por el número total de familias (75.000) y dividiéndolo por los años del período de construcción (10 años): el resultado son 48 millones de dólares.

- La contribución estimada de cada familia, 1.600 dólares, no se incluye en el flujo de caja porque no se trata de efectivo. Como se explicó anteriormente, esta suma representa el valor de su propia tierra.

- Los pagos realizados por las familias por concepto de amortización del principal y de los intereses se incorporan como ingresos del proyecto.

- Los gastos generales y administrativos anuales relativos a la cantidad amortizada se estiman en un 5\%.

- Se incluye un valor residual del 10\% (4.800.000 dólares) entre el año 10 y el año 19.

- Se estima que cada grupo de casas tendrá una vida útil de 20 años.

En el anexo 2 se presenta la evaluación financiera según los parámetros ya enumerados. A continuación se presentan el resumen de los resultados, en el cuadro 4 , y los análisis de la sensibilidad, en el gráfico 2 , y del riesgo, en el gráfico 3 . 
CUADRO 4

\section{Resultados del proyecto de evaluación financiera}

Tasa de descuento

$5,5 \%$

Valor actual neto (VAN)

52847178 dólares

Tasa interna de rentabilidad (TIR)

$7,25 \%$

Fuente: Elaboración propia sobre la base de datos del anexo 2.

GRÁFICO 2

Análisis de la sensibilidad

(En dólares)

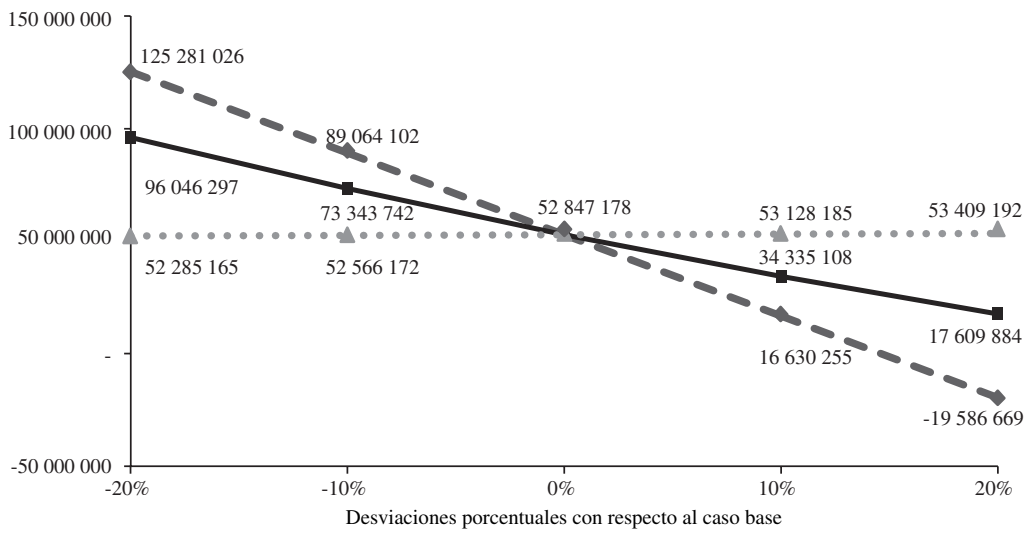

$\longrightarrow$ Préstamos para la vivienda $\quad \longrightarrow$ Tasa de descuento $\quad \ldots$ Valor residual

\begin{tabular}{|c|c|c|c|c|c|}
\hline Variable & $-20 \%$ & $-10 \%$ & $0 \%$ & $10 \%$ & $20 \%$ \\
\hline Préstamos para la vivienda & 125281026 & 89064102 & 52847178 & 16630255 & -19586669 \\
\hline Tasa de descuento & 96046297 & 73343742 & 52847178 & 34335108 & 17609884 \\
\hline Valor residual & 52285165 & 52566172 & 52847178 & $53 \quad 128 \quad 185$ & 53409192 \\
\hline
\end{tabular}

Fuente: Elaboración propia sobre la base de datos del anexo 2.

GRÁFICO 3

\section{Análisis del riesgo}

20000 ensayos

Vista dividida

19907 mostrados

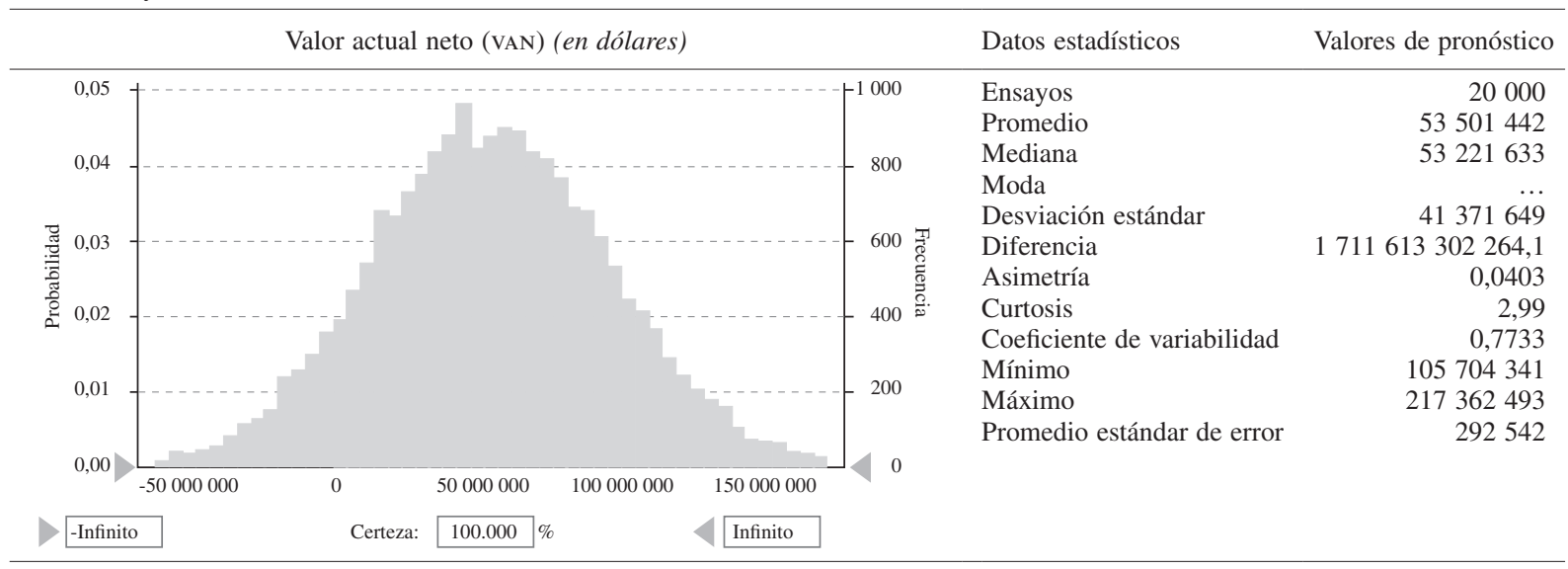

Fuente: Elaboración propia. 


\section{e) Observaciones con respecto al flujo de caja}

La AFD, como entidad que financia el proyecto, aplicará la tasa de descuento del 5,5\% al coste de financiamiento. Según puede observarse en el cuadro 4, el vaN del proyecto es de 52.847.178 dólares de modo que la inversión es viable. El vAN cobra mayor relevancia al tratarse de un proyecto social que no supone un costo para las finanzas públicas del Paraguay. Además, si se evalúa el proyecto teniendo en cuenta la totalidad de la economía nacional, deberían añadirse otros ingresos y gastos provenientes de los llamados "precios virtuales" (precios sombra) y aplicarse una tasa de descuento social $^{7}$. La combinación de estos elementos mejoraría aún más el vaN.

Con el fin de analizar la sensibilidad y el riesgo del proyecto, se utilizó el programa Crystal Ball. Se seleccionaron tres variables críticas: los préstamos para la vivienda del primer año, el valor residual del undécimo año y la tasa de descuento. En el gráfico 2 (análisis de la sensibilidad) se muestra que los préstamos que se conceden constituyen la variable más sensible, seguidos por la tasa de descuento y, en tercer lugar, el valor residual. En el gráfico 3 (análisis del riesgo) se encuentran los resultados de 20.000 simulaciones. Estos son los principales: el VAN medio se sitúa en 53.501.442 dólares; la desviación estándar (el propio riesgo), en 41.371.649 dólares; el coeficiente de variabilidad (desviación estándar/VAN medio) es del 77,33\%; el valor mínimo asciende a 105.704.341 dólares, y el valor máximo a 217.362.493 dólares. Todos los resultados del análisis del riesgo corroboran con firmeza la evaluación del proyecto. En este sentido, sobre la base de las hipótesis de normalidad en la distribución de probabilidad, hay un $68 \%$ de probabilidades de que el vAN se sitúe entre los 12.129.793 dólares (la resta de 41.371.649 a 53.501.442) y 94.873.091 dólares (la suma de 53.501.442 y 41.371.649).

${ }^{7}$ La elección de la tasa de descuento que se debe aplicar en el análisis de costos y beneficios de un proyecto social es uno de los aspectos más polémicos de este ámbito de la economía.

\section{Emisión de bonos de largo plazo por parte de la AFD}

a) ¿Cómo pueden financiarse los primeros diez años de flujos negativos?

Esta es el principal interrogante que permanece sin respuesta al observar, en el cuadro 5, que los resultados de los flujos son negativos durante los primeros diez años.

En el artículo $1^{\circ}$ de la Ley 2640, por la que se creó la Agencia Financiera de Desarrollo (AFD), se expresa que, a objeto de obtener otros recursos, la AFD podrá, mediante resolución del Directorio, emitir bonos en moneda nacional o extranjera con garantía del Estado, previa autorización del Congreso Nacional en cada caso. Asimismo, en el párrafo g del artículo 5, se agrega que con miras al desarrollo de programas habitacionales, urbanísticos y demás acciones dirigidas a disminuir el déficit habitacional, la AFD deberá obligatoriamente proveer fondos para financiar programas habitacionales y viviendas individuales. Además, en el Artículo 98 de la Ley 4848/13, por la que se aprobó el presupuesto general del Paraguay para 2013, se autoriza a la AFD a emitir y mantener en circulación bonos nominativos y negociables, con garantía del Tesoro Público, hasta por un monto de 400.000 millones de guaraníes (aproximadamente 90 millones de dólares).

A pesar de la inmadurez del mercado de valores del Paraguay, las posibilidades ofrecidas por la legislación pueden aprovecharse en tres dimensiones diferentes, de tal manera que: i) la AFD adquiera los recursos financieros necesarios para cubrir la diferencia de los flujos durante los primeros diez años; ii) las emisiones consecutivas estimulen el mercado de valores paraguayo y se facilite la democratización del capital en el Paraguay, y iii) los analistas y asesores de inversiones potenciales puedan apreciar mayor dinamismo en la bolsa del país. Como se menciona más adelante, también dicha legislación supondría una valiosa oportunidad para los mercados bursátiles de los países del Mercado Común del Sur (MERCOSUR), ya que podrían participar en las transacciones, y así pasar de las palabras a la acción en materia de solidaridad regional.

CUADRO 5

Flujos negativos durante los primeros diez años

(En dólares)

\begin{tabular}{ccccccccccc}
\hline \multicolumn{10}{c}{ Años } \\
\hline 2015 & 2016 & 2017 & 2018 & 2019 & 2020 & 2021 & 2022 & 2023 & 2024 \\
\hline-45228000 & -42456000 & -39684000 & -36912000 & -31140000 & -25541250 & -20115750 & -14863500 & -9784500 & -4878750 \\
\hline
\end{tabular}

Fuente: Elaboración propia. 
b) El estado actual del financiamiento de vivienda social

Como se mencionó en la Introducción, en el Paraguay no existe una política de vivienda propiamente tal, si bien el gobierno y algunas ONG han llevado a cabo programas específicos de pequeña envergadura dedicados a la vivienda social. En este artículo, sin embargo, se estudia la manera en que el Gobierno del Paraguay ha financiado los programas de vivienda social implementados de forma aislada en las últimas décadas. El financiamiento provenía sobre todo de fuentes externas e internas gestionadas por el Consejo Nacional de la Vivienda (CONAVI) y el Banco Nacional de Ahorro y Préstamo para la Vivienda (BNAPV) y supervisadas por otro ente del gobierno central. El CONAVI y el BNAPV canalizaban los fondos a través de bancos comerciales y sociedades de ahorro y préstamo considerados "aptos", que se encargaban de las operaciones de crédito de cara a los beneficiarios. En la gran mayoría de los casos, los préstamos se concedieron con intereses subvencionados; lamentablemente, el principal segmento beneficiado fue la población de ingresos medio-altos. En el gráfico 4 se ilustra esta situación.

Como puede observarse, las ONG ocupan un lugar prominente en el gráfico 4. Esto se debe al importante papel que desempeñaron en la situación de la vivienda en el país en los años ochenta. Se puede deducir a partir del gráfico 4 que la estructura operativa y la continuidad de estos programas se sostenían gracias a las finanzas públicas. Paradójicamente, la función del BNAPV estaba prácticamente reducida al control de las sociedades de ahorro y préstamo, que constituyen solo un pequeño componente del sistema financiero del Paraguay. El organismo oficial que supervisaba a los bancos participantes era la Superintendencia de Bancos.

Puede concluirse que el plan de financiamiento no funcionó porque no remedió la grave escasez de vivienda. Como ya se expuso, existe un déficit urgente de 450.000 viviendas que afecta directamente a 1,8 millones de personas, el 27,3\% de la población del Paraguay. En este artículo se presenta una propuesta financiera factible para hacer frente a esta situación crítica.

GRÁFICO 4

Paraguay: panorámica del financiamiento de vivienda social, 1970-2000

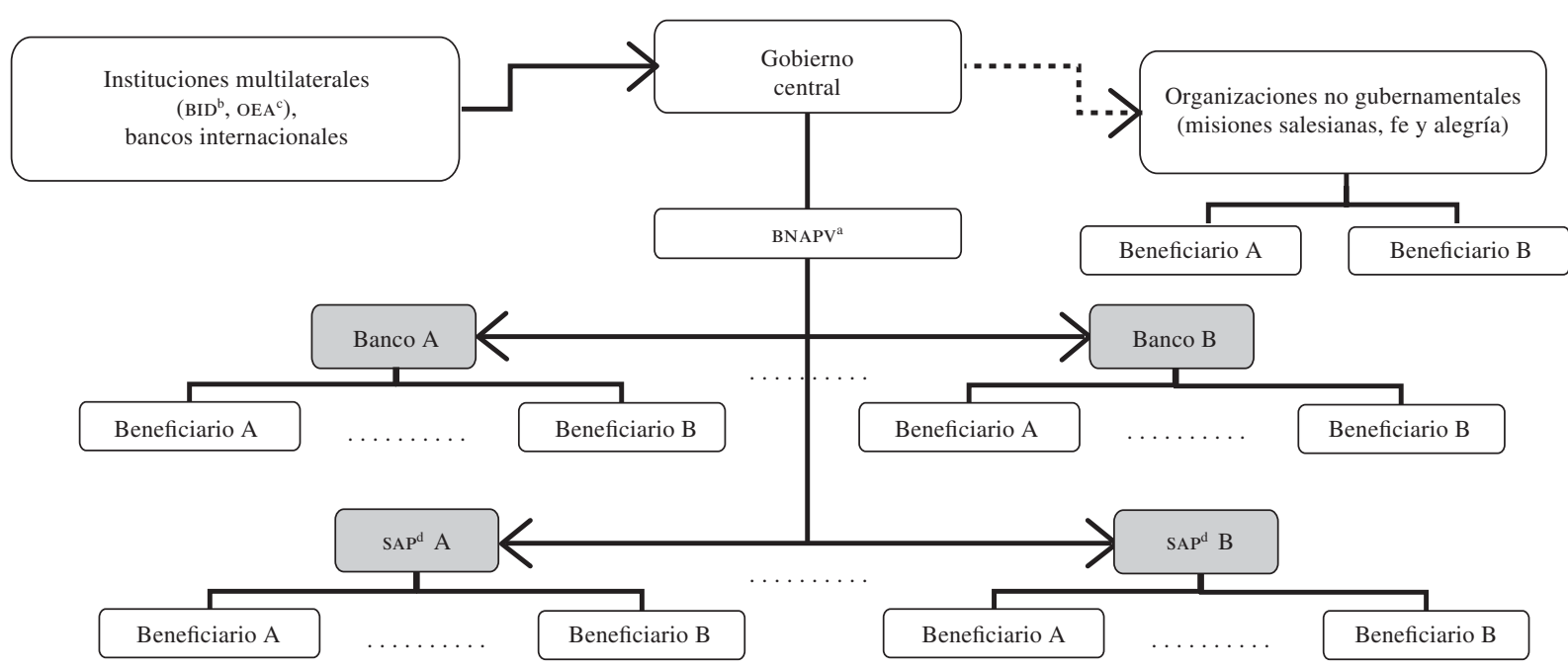

Fuente: Elaboración propia.

a Banco Nacional de Ahorro y Préstamo para la Vivienda.

b Banco Interamericano de Desarrollo.

c Organización de los Estados Americanos.

d Sociedad de Ahorro y Préstamo. 


\section{c) Propuesta de emisión de bonos de Vivienda} Económica de Interés Social (VEIS)

La propuesta consiste en una transacción de ingeniería financiera en la que pueden participar instituciones tanto del sector público como del privado. Se trata de una emisión de bonos por parte de la AFD que estarán respaldados por los créditos hipotecarios concedidos por las instituciones financieras intermediarias antes mencionadas. Estas instituciones, en calidad de entidades financieras de primer piso, descontarán a su vez las hipotecas a través de la AFD, que actuará como entidad de segundo piso. La AFD, por lo tanto, adquiere un papel estratégico y se sitúa en el centro de la propuesta. A continuación, se describen las etapas del proceso y las organizaciones que participan en este.

\section{d) Etapas del proceso y organizaciones participantes}

El modelo de financiamiento reúne los esfuerzos del sector público (la AFD, con el apoyo del gobierno central, el Ministerio de Hacienda, el Banco Central del Paraguay y la Comisión Nacional de Valores) y el sector privado (11 cooperativas de préstamo y una sociedad de ahorro y préstamo, como organizaciones de primer piso, y la Bolsa de Valores y Productos de Asunción (BVPASA), los bancos comerciales y otras instituciones financieras, como negociadores de los bonos emitidos). Las etapas y la intervención de las organizaciones de la alternativa propuesta se desarrollarían de la siguiente forma:

i) Los beneficiarios negocian y firman la hipoteca para el financiamiento de sus viviendas con las cooperativas o las sociedades de ahorro y préstamo. Aparte de los requisitos legales inherentes, el contrato debe incluir las condiciones que han de cumplir los beneficiarios.

ii) Las cooperativas y las sociedades de ahorro y préstamo agrupan las hipotecas formalizadas y las venden a la AFD, aunque mantienen los derechos de servicio.

iii) La AFD compra las hipotecas y, tal y como dicta la Ley por la que se creó esta agencia, negocia con el gobierno central dos cuestiones principales: por una parte, la autorización para emitir nuevos valores en bolsa, respaldados por los respectivos grupos de hipotecas, y por otra, una garantía gubernamental (emitida por el Banco Central del Paraguay o por el Ministerio de Hacienda) de la emisión de estos valores. En términos bursátiles, esta modalidad de emisión se conoce como "titulización" o "securitización", y en el Paraguay se rige por la Ley 1036/97 que crea y regula las sociedades securitizadoras. Para conservar el nombre que la AFD utiliza en sus estados financieros (Vivienda Económica de Interés Social), estos valores se llamarán "bonos veIs".

iv) Una vez obtenidas las aprobaciones pertinentes del gobierno central con relación a la emisión al mercado de valores y a la mencionada garantía, la AFD negocia con la Comisión Nacional de Valores, que depende del Ministerio de Comercio e Industria, y con la BVPASA la emisión de las primeras obligaciones al mercado primario.

v) La Comisión Nacional de Valores, una vez realizado un análisis previo, autoriza a la BVPASA como primera emisora en el mercado secundario.

vi) Los bonos son adquiridos por los bancos comerciales, el Banco Central del Paraguay ${ }^{8}$, el Banco Nacional de Fomento, compañías aseguradoras e inversionistas en general.

vii) Los fondos recaudados en el mercado de valores por la venta de los bonos VEIS se transfieren a la AFD. Simultáneamente, la AFD los entrega como pago de las hipotecas compradas a las cooperativas y a las sociedades de ahorro y préstamo.

viii) Estas entidades transfieren los fondos a la cuenta bancaria de cada familia prestataria, que los utiliza para pagar a los constructores de las viviendas.

ix) Posteriormente, a cada vencimiento, los beneficiarios pagan su hipoteca a las cooperativas y a las sociedades de ahorro y préstamo. A su vez, estas entidades transfieren los fondos a la AFD para saldar su deuda. Por razones obvias, en este artículo no se entra en detalles sobre los procedimientos que tienen lugar entre las diferentes instituciones, $\mathrm{u}$ otras cuestiones relacionadas con la negociación o la ingeniería financiera.

\footnotetext{
${ }^{8}$ En virtud del Artículo 16 de la Ley 42/89, el "Banco Central del Paraguay adquirirá bonos del Banco con la denominación de 'Bonos de Viviendas Económicas de Interés Social', hasta un monto equivalente al 5\% (cinco por ciento) de los ahorros depositados en las Sociedades del Sistema".
} 
e) Características de la primera emisión de bonos VEIS en 2015

En el cuadro 6 se pueden observar las características que se prevé tendrá la primera emisión de bonos.

Todas las características generales mostradas se basan en emisiones recientes de bonos del Tesoro Público del Paraguay en el mercado de valores de Asunción. Por ejemplo, la tasa de interés de los últimos bonos del Tesoro a diez años, emitidos en enero de 2013 por 500 millones de dólares, fue del 4,6\%. Por lo tanto, es apropiado considerar una tasa de interés del $5 \%$ para la emisión de estos bonos. Asimismo, el porcentaje de impuestos se aplica de conformidad con la legislación fiscal.

Datos generales de los primeros bonos veIs emitidos:

- Ingresos netos de la AFD en el momento de la emisión: 44.323 .440 dólares.

- Interés trimestral: 565.350 dólares.

- Total pagado en el momento del reembolso: 45.228.000 dólares.

- Los intereses generarán un ahorro fiscal anual del 35\% con respecto al año anterior. Entre 2017 y 2026, cada mes de junio se abonarán 791.400 dólares al Ministerio de Hacienda.

- Los costos de la emisión y la prima de reembolso generarán, durante el año siguiente, un ahorro fiscal de 31.660 dólares.

En el cuadro 7 se aprecia que el costo anual de emitir los bonos es del $4,16 \%$, mientras que el rendimiento anual bruto y neto para los inversionistas es del 5,09\% y del $3,8 \%$, respectivamente.

\section{f) Balance general del proyecto para la $A F D$}

En términos generales, la emisión de bonos del primer año (por un valor de 45.228.000 dólares) representaría un aumento del $11,8 \%$ del total de los activos de la AFD en 2013 y un incremento del 42,7\% de sus pasivos en forma de bonos y obligaciones. A la fecha del 31 de diciembre de 2013, el total de los activos de la AFD era de 384,1 millones de dólares, y los pasivos en forma de bonos emitidos equivalían a 106,0 millones de dólares. Por lo tanto, este proyecto tendría un impacto económico sustancial en la institución. A continuación, en el cuadro 8, se presenta la estructura de los diferenciales totales del proyecto.

La AFD obtendría un diferencial del 3,73\% a partir de sus nuevos pasivos (bonos) y activos (préstamos a las instituciones financieras intermediarias). Es decir, el resultado de restar el costo efectivo de la emisión de bonos $(3,52 \%)$ a la tasa de interés efectiva de los préstamos $(7,25 \%)$.

En el caso de las instituciones financieras intermediarias, el diferencial sería del $4,44 \%$, que resulta de la diferencia entre la tasa de interés efectiva de las hipotecas $(11,60 \%)$ y el costo efectivo del financiamiento $(7,25 \%)$. Este margen se considera adecuado para un banco estatal y para cooperativas que participan en un proyecto de vivienda social en el Paraguay.

Valor de la primera emisión de bonos VEIS: $\mathbf{4 5 . 2 2 8 . 0 0 0 ~ d o ́ l a r e s ~}$

Valor nominal de los bonos veIs

Cantidad de bonos emitidos

Tipo de emisión

Plazo de suscripción

Tasa de interés

Modalidad de pago

Períodos subanuales

Fecha de amortización

Número de trimestres

Número de años

Precio de amortización

Retención fiscal

Tasa de gastos administrativos

Tasa de impuesto sobre el ingreso

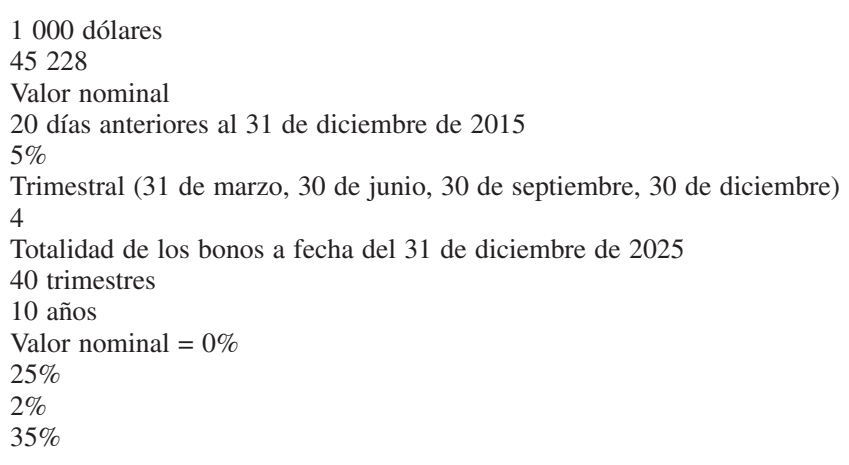

Fuente: Elaboración propia.

Nota: veIs: Bonos de Vivienda Económica de Interés Social. 
Costo trimestral del bono para la AFD

Costo anual del bono para la AFD

Rentabilidad trimestral para el inversionista (bruta y neta)

Rentabilidad anual para el inversionista (bruta y neta)

\section{$1,02 \%$}

$4,16 \%$

$\begin{array}{ll}1,25 \% & 0,94 \% \\ 5,09 \% & 3,8 \%\end{array}$

Fuente: Elaboración propia.

Nota: VEIS: Bonos de Vivienda Económica de Interés Social.

\section{Estructura de los diferenciales}

\begin{tabular}{|c|c|c|c|c|c|}
\hline & \multicolumn{2}{|c|}{ Tasa de interés nominal } & \multicolumn{2}{|c|}{ Tasa de interés efectiva } & \multirow[t]{2}{*}{ Diferencial } \\
\hline & Costo de emisión & Rentabilidad & Costo de emisión & Rentabilidad & \\
\hline Bonos VeIs & $5 \%$ & $5,09 \%$ & $3,52 \%$ & $3,8 \%$ & \\
\hline AFD a IFI & & $5,5 \%$ & & $7,25 \%$ & $3,73 \%$ \\
\hline IFI a beneficiarios & & $9,5 \%$ & & $11,69 \%$ & $4,44 \%$ \\
\hline
\end{tabular}

Fuente: Elaboración propia.

Nota: VeIs: Bonos de Vivienda Económica de Interés Social; AFD: Agencia Financiera de Desarrollo; IFI: Instituciones financieras intermediarias.

\section{g) Proyección de la situación}

Como antes se señaló, la emisión de bonos durante los primeros diez años ascenderá a un total de 270,6 millones de dólares. Esta cifra representa una cantidad perfectamente negociable en el mercado financiero del Paraguay. En los últimos tres años, se han negociado en el mercado de valores de Asunción 350 millones de dólares en bonos, y, entre enero de 2013 y agosto de 2014, el gobierno emitió 1.500 millones de dólares que fueron negociados en su totalidad en los mercados internacionales.

En el gráfico 5 se advierte cómo se estructuraría el mercado en relación con el financiamiento de las viviendas sociales.

Cabe mencionar que, si bien el programa daría pie a la promoción y el desarrollo de fuentes alternativas de financiamiento, no todas serían facilidades para la AFD, a pesar de la garantía del gobierno central. La AFD estaría expuesta a una serie de riesgos, en particular relacionados con la liquidez, el mercado y el riesgo de pago anticipado.
- $\quad$ El riesgo de liquidez se refiere a las emisiones planificadas que dependerán básicamente de la disponibilidad de recursos financieros en el mercado secundario del Paraguay.

- $\quad$ El riesgo del mercado concierne a un asunto más allá del riesgo de la propia volatilidad de las inversiones a largo plazo; existe la duda de si el mercado de valores paraguayo será capaz de absorber las emisiones de bonos anuales. En este contexto, conviene considerar la participación de inversionistas de los países vecinos. Esta sería la ocasión propicia para pasar de las palabras a la acción en lo que se refiere a la solidaridad del MERCOSUR. En efecto, la Bolsa de Valores de São Paulo (BOVEsPa) y el Mercado de Valores de Buenos Aires (MERVAL) podrían participar de forma activa en la operación. Ambos mercados ya se hallan involucrados en otras emisiones de bonos de América Latina.

- $\quad$ El riesgo de pago anticipado radica en la probabilidad de que se reduzca la tasa de interés en el mercado, lo que motivaría a los prestatarios a adelantar el pago de su hipoteca. 


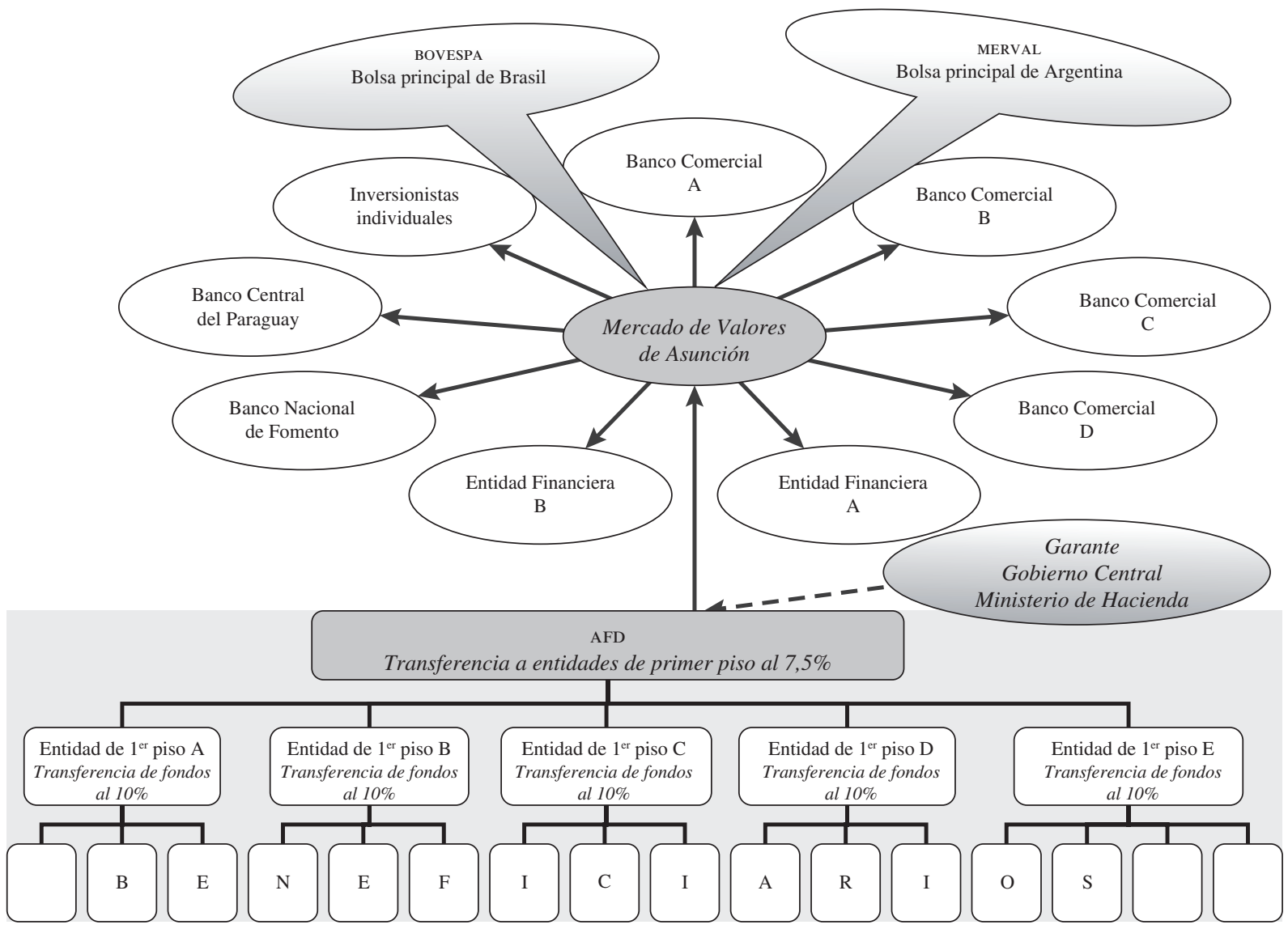

Fuente: Elaboración propia.

\section{Conclusiones}

En la mayoría de los países de América Latina no existen políticas de vivienda coordinadas, sino proyectos específicos llevados a cabo por agencias de desarrollo y ONG, que solo benefician a un reducido número de personas. La AFD ha puesto en marcha algunos proyectos, pero resultan claramente insuficientes.

La alternativa propuesta es factible: la suma del proyecto, 600 millones de dólares, equivale aproximadamente a un $2,07 \%$ del producto interno bruto (PIB) del Paraguay ${ }^{9}$, por lo que no representa una

\footnotetext{
${ }^{9}$ Según el Banco Mundial, en 2013 el PIB del Paraguay era de 29.010 millones de dólares corrientes.
}

carga demasiado grande para la economía del país. Los fondos se podrían generar siempre que las instituciones participantes se coordinaran adecuadamente. Sin embargo, el Gobierno del Paraguay, a través de la AFD, tendría que hacer gala de un firme compromiso y una sólida voluntad política. La magnitud del proyecto podría suponer un problema para la AFD en términos de gestión financiera, pero el alarmante déficit de vivienda en el Paraguay exige este tipo de medidas. Durante décadas ya se han aplicado políticas en forma de parche, sin ningún resultado.

El proyecto beneficiaría a unas 75.000 familias de ingresos medios-bajos cuyo acceso al crédito en el sistema financiero formal del Paraguay es limitado. De 
esta forma tendrían que pagar el $16 \%$ de sus ingresos esperados. El objetivo principal de la presente propuesta es facilitar al 4,5\% de la población (300.000 personas, o 75.000 familias de cuatro componentes) el acceso a una vivienda estándar. A su vez, esto contribuiría a estimular el consumo interno del país, a través del conocido efecto multiplicador de la construcción en la economía nacional. También el sistema financiero se vería fortalecido, ya que más hogares contarían con una propiedad que ofrecer como aval para acceder a nuevos créditos, lo que incrementaría la riqueza de la población y con ella la de la nación.

El Gobierno del Paraguay, por intermedio de la AFD, tendría que presionar al mercado, romper el hielo, negociar con los participantes, emitir los primeros bonos y mostrar a los potenciales inversionistas y a las agencias de calificación internacionales que el proyecto es viable. Así, el proyecto obtendrá el reconocimiento y la aprobación del mercado siempre que se cumplan estas dos condiciones: en primer lugar, que el programa de construcción avance en los primeros dos años y los inversionistas lo observen y se den cuenta del importante papel que desempeñan en la economía real, y, en segundo lugar, que los beneficios trimestrales se abonen de manera regular.

Esta opción de financiamiento de viviendas sociales nace de la investigación académica y de experiencias profesionales en el ámbito del desarrollo en varios países de América Latina. Los autores son conscientes de que su propuesta (así como las estimaciones y cálculos sobre la base de continuos ensayos y errores) constituye un marco teórico global. Cada uno de los procesos tendría que ser sometido al correspondiente análisis técnico antes de ponerlo en práctica en el mundo real. No obstante, los autores se muestran convencidos de la viabilidad económica del proyecto. 
ANEXO 1

Cuadro de amortización de los préstamos para las familias (En dólares)

\begin{tabular}{|c|c|c|c|c|c|c|c|c|c|}
\hline \multirow{2}{*}{ Años } & \multicolumn{3}{|c|}{ Principal } & \multicolumn{2}{|c|}{ Interés } & \multicolumn{2}{|c|}{$\begin{array}{l}\text { Costos generales } \\
\mathrm{y} \text { administrativos }\end{array}$} & \multicolumn{2}{|c|}{ Total para cada familia } \\
\hline & Cuotas & Acumulado & Balance & Anual & Acumulado & Anuales & Acumulados & Pagado & Acumulado \\
\hline 1 & & 0,0 & 6400,0 & 608,0 & 608,0 & 30,4 & 30,4 & 638,4 & 638,4 \\
\hline 2 & & 0,0 & 6400,0 & 608,0 & 1216,0 & 30,4 & 60,8 & 638,4 & 1276,8 \\
\hline 3 & & 0,0 & 6400,0 & 608,0 & 1824,0 & 30,4 & 91,2 & 638,4 & 1915,2 \\
\hline 4 & & 0,0 & 6400,0 & 608,0 & 2432,0 & 30,4 & 121,6 & 638,4 & 2553,6 \\
\hline 5 & 400,0 & 400,0 & 6000,0 & 570,0 & 3002,0 & 28,5 & 150,1 & 998,5 & 3552,1 \\
\hline 6 & 400,0 & 800,0 & 5600,0 & 532,0 & 3534,0 & 26,6 & 176,7 & 958,6 & 4510,7 \\
\hline 7 & 400,0 & 1200,0 & 5200,0 & 494,0 & 4028,0 & 24,7 & 201,4 & 918,7 & 5429,4 \\
\hline 8 & 400,0 & 1600,0 & 4800,0 & 456,0 & 4484,0 & 22,8 & 224,2 & 878,8 & 6308,2 \\
\hline 9 & 400,0 & 2000,0 & 4400,0 & 418,0 & 4902,0 & 20,9 & 245,1 & 838,9 & 7147,1 \\
\hline 10 & 400,0 & 2400,0 & 4000,0 & 380,0 & 5282,0 & 19,0 & 264,1 & 799,0 & 7946,1 \\
\hline 11 & 400,0 & 2800,0 & 3600,0 & 342,0 & 5624,0 & 17,1 & 281,2 & 759,1 & 8705,2 \\
\hline 12 & 400,0 & 3200,0 & 3200,0 & 304,0 & 5928,0 & 15,2 & 296,4 & 719,2 & 9424,4 \\
\hline 13 & 400,0 & 3600,0 & 2800,0 & 266,0 & 6194,0 & 13,3 & 309,7 & 679,3 & 10103,7 \\
\hline 14 & 400,0 & 4000,0 & 2400,0 & 228,0 & 6422,0 & 11,4 & 321,1 & 639,4 & 10743,1 \\
\hline 15 & 400,0 & 4400,0 & 2000,0 & 190,0 & 6612,0 & 9,5 & 330,6 & 599,5 & 11342,6 \\
\hline 16 & 400,0 & 4800,0 & 1600,0 & 152,0 & 6764,0 & 7,6 & 338,2 & 559,6 & 11902,2 \\
\hline 17 & 400,0 & 5200,0 & 1200,0 & 114,0 & 6878,0 & 5,7 & 343,9 & 519,7 & 12421,9 \\
\hline 18 & 400,0 & 5600,0 & 800,0 & 76,0 & 6954,0 & 3,8 & 347,7 & 479,8 & 12901,7 \\
\hline 19 & 400,0 & 6000,0 & 400,0 & 38,0 & 6992,0 & 1,9 & 349,6 & 439,9 & 13341,6 \\
\hline 20 & 400,0 & 6400,0 & 0,0 & 0,0 & 6992,0 & 0,0 & 349,6 & 400,0 & 13741,6 \\
\hline & 6400,0 & & & 6992,0 & & 349,60 & & 13741,6 & \\
\hline
\end{tabular}

Fuente: Elaboración propia sobre la base de datos oficiales de la Dirección General de Encuestas, Estadísticas y Censos (DGEEC), el Banco Central del Paraguay (BCP) y la Agencia Financiera de Desarrollo (AFD). 
ANEXO 2

Paraguay: flujo de caja del proyecto de vivienda social

(En dólares)

\begin{tabular}{|c|c|c|c|c|c|c|c|}
\hline Años & $\begin{array}{l}\text { Total del } \\
\text { principal } \\
\text { recaudado }\end{array}$ & $\begin{array}{l}\text { Total del interés } \\
\text { recaudado }\end{array}$ & $\begin{array}{l}\text { Ingresos generales } \\
\text { y administrativos }\end{array}$ & $\begin{array}{l}\text { Valores } \\
\text { residuales }\end{array}$ & $\begin{array}{c}\text { Total entradas } \\
\text { de efectivo }\end{array}$ & $\begin{array}{l}\text { Total salidas } \\
\text { de efectivo }\end{array}$ & Flujo de caja \\
\hline 0 & 0 & 2640000 & 132000 & & 2772000 & -48000000 & -45228000 \\
\hline 1 & 0 & 5280000 & 264000 & & 5544000 & -48000000 & -42456000 \\
\hline 2 & 0 & 7920000 & 396000 & & 8316000 & -48000000 & -39684000 \\
\hline 3 & 0 & 10560000 & 528000 & & 11088000 & -48000000 & -36912000 \\
\hline 4 & 3000000 & 13200000 & 660000 & & 16860000 & -48000000 & -31140000 \\
\hline 5 & 6000000 & 1675000 & 783750 & & 22458750 & -48000000 & -25541250 \\
\hline 6 & 9000000 & 17985000 & 899250 & & 27884250 & -48000000 & -20115750 \\
\hline 7 & 12000000 & 20130000 & 1006500 & & 33136500 & -48000000 & -14863500 \\
\hline 8 & 15000000 & 22110000 & 1105500 & & 38215500 & -48000000 & -9784500 \\
\hline 9 & 18000000 & 23925000 & 1196250 & & 43121250 & -48000000 & -4878750 \\
\hline 10 & 21000000 & 22935000 & 1146750 & 4800000 & 49881750 & & 49881750 \\
\hline 11 & 24000000 & 21780000 & 1089000 & 4800000 & 51669000 & & 51669000 \\
\hline 12 & 27000000 & 20460000 & 1023000 & 4800000 & 53283000 & & 53283000 \\
\hline 13 & 30000000 & 18975000 & 948750 & 4800000 & 54723750 & & 54723750 \\
\hline 14 & 30000000 & 17325000 & 866250 & 4800000 & 52991250 & & 52991250 \\
\hline 15 & 30000000 & 15675000 & 783750 & 4800000 & 51258750 & & 51258750 \\
\hline 16 & 30000000 & 14025000 & 701250 & 4800000 & 49526250 & & 49526250 \\
\hline 17 & 30000000 & 12375000 & 618750 & 4800000 & 47793750 & & 47793750 \\
\hline 18 & 30000000 & 10725000 & 536250 & 4800000 & 46061250 & & 46061250 \\
\hline 19 & 30000000 & 9075000 & 453750 & 4800000 & 44328750 & & 44328750 \\
\hline 20 & 27000000 & 7425000 & 371250 & & 34796250 & & 34796250 \\
\hline 21 & 24000000 & 5940000 & 297000 & & 30237000 & & 30237000 \\
\hline 22 & 21000000 & 4620000 & 231000 & & 25851000 & & 25851000 \\
\hline 23 & 18000000 & 3465000 & 173250 & & 21638250 & & 21638250 \\
\hline 24 & 15000000 & 2475000 & 123750 & & 17598750 & & 17598750 \\
\hline 25 & 12000000 & 1650000 & 82500 & & 13732500 & & 13732500 \\
\hline 26 & 9000000 & 990000 & 49500 & & 10039500 & & 10039500 \\
\hline 27 & 6000000 & 495000 & 24750 & & 6519750 & & 6519750 \\
\hline 28 & 3000000 & 165000 & 8250 & & 3173250 & & 3173250 \\
\hline
\end{tabular}

Tasa de descuento

Valor actual neto (VAN)

Tasa interna de rentabilidad (TIR)

\section{$5,50 \%$}

52847178 dólares

$7,25 \%$

Fuente: Elaboración propia. 
ANEXO 3

Flujo de caja de la emisión de bonos VEIS de 2015

(En dólares)

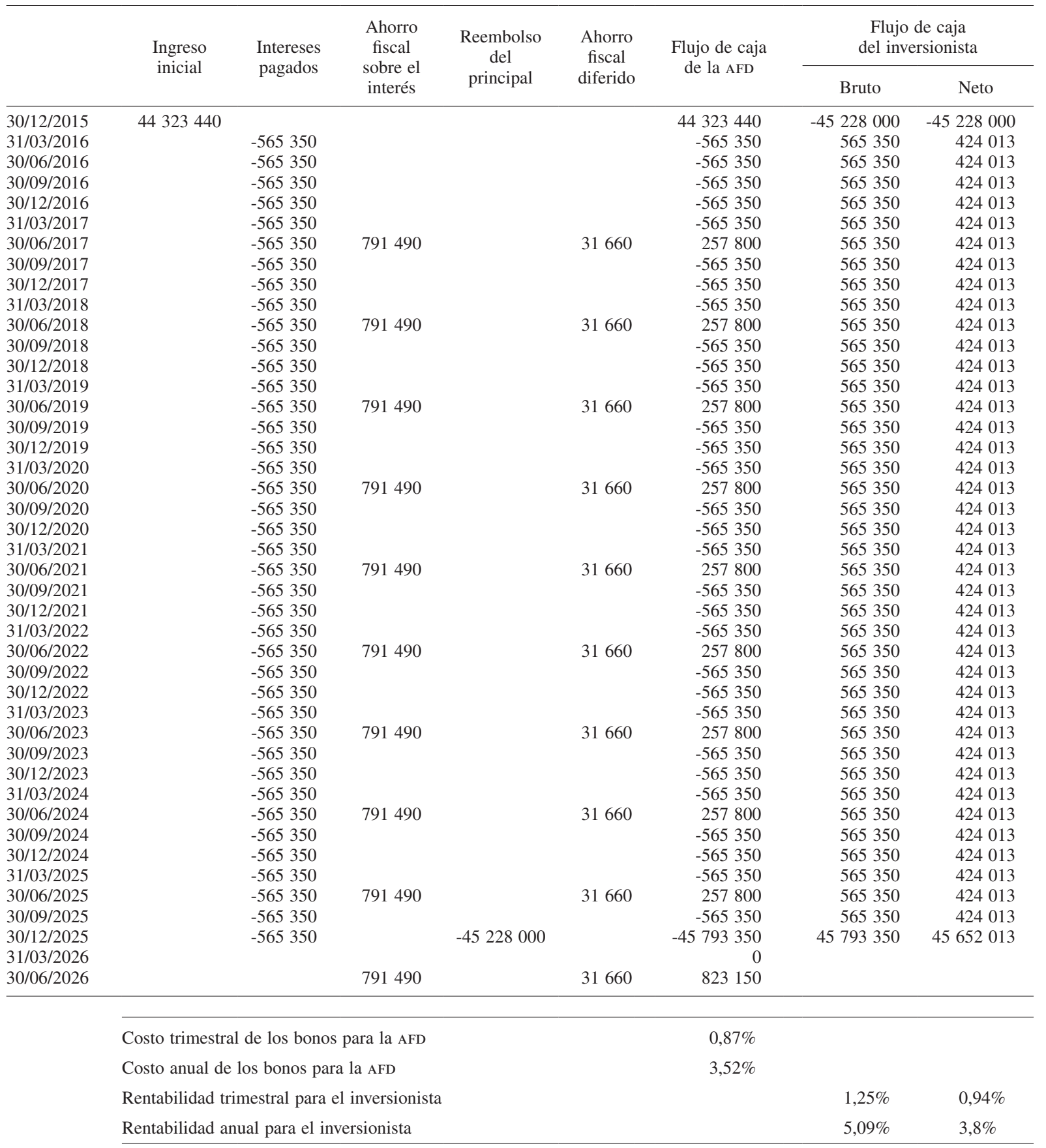

Fuente: Elaboración propia. 


\section{Bibliografía}

Acemoglu, Daron, Simon Johnson y James A. Robinson (2002), "Reversal of fortune: geography and institutions in the making of the modern world income distribution", The Quarterly Journal of Economics, vol. 117, $\mathrm{N}^{\circ}$ 4, Cambridge, Massachusetts, The MIT Press.

AFD (Agencia Financiera de Desarrollo) (2013a), "Llamado a licitación pública para la emisión, negociación, colocación y mantenimiento en circulación de bonos físicos de la agencia financiera de desarrollo, Ley $\mathrm{N}^{\circ} 4.848 / 13$ " [en línea] http://www.afd.gov.py/userfiles/file/ Emisión\%20Bonos\%20 Físicos\%20AFD\%20de\%205\%20a\%2010\%20Años\%20 (FL181213).pdf.

(2013b), "Estado de la situación patrimonial", 30 de junio [en línea] http://www.afd.gov.py /serfiles/file/Balance\%20 segundo\%20trimestre\%202013.pdf.

Bauer, Peter (2000), From Subsistence to Exchange and Other Essays, Princeton, Princeton University Press.

BCP (Banco Central del Paraguay) (2014), "Anexo estadístico del informe económico" [en línea] https://www.bcp.gov.py/anexoestadistico-del-informe-economico-i365.

Bouillon, César P. (2012), Un espacio para el desarrollo: los mercados de vivienda en América Latina y el Caribe, Washington, D.C., Banco Interamericano de Desarrollo.

Coccato, Marcelo (1996), Alternatives to Home Ownership: Rental and Shared Submarkets in Informal Settlements, Montreal, McGill University.

Connolly, Priscilla (1997), "El financiamiento de vivienda en México" [en línea] http://infonavit.janium.net/janium /UAM/ Documentos/19752.pdf.

Daphnis, Franck (2006), "Microfinanzas para vivienda: hacia una definición", Microfinanzas para vivienda: una guía para la práctica, Franck Daphnis y Bruce Ferguson (eds.), San José, Hábitat para la Humanidad Internacional.

De Leeuw, Frank (1971), "The demand for housing: a review of crosssection evidence", The Review of Economic and Statistics, vol. 53, $\mathrm{N}^{\circ} 1$, Cambridge, Massachusetts, The MIT Press.

DGEEC (Dirección General de Estadísticas, Encuestas y Censos) (2012), "Encuesta Permanente de Hogares (EPH)" [en línea] http://www.dgeec.gov.py/Publicaciones/Biblioteca/EPH2012/ principales_resultados_EPH2012.pdf.

(2011a), "Encuesta Permanente de Hogares (EPH)" [en línea] http://www.dgeec.gov.py/Publicaciones/Biblioteca/ EPH2011/ Boletin\%20de\%20Pobreza\%20e\%20Ingresos\%202011.pdf.

(2011b), "Principales resultados de pobreza y distribución del ingreso" [en línea] http://www.dgeec.gov.py/Publicaciones/ Biblioteca/EPH2011/Boletin\%20de\%20Pobreza\%20e\%20 Ingresos\%202011.pdf.

De Soto, Hernando (2000), The Mystery of Capital: Why Capitalism Triumphs in the West and Fails Everywhere Else, Nueva York, Basic Books.

Fallis, George y Lawrence B. Smith (1984), "Uncontrolled prices in a controlled market: the case of rent controls", The American Economic Review, vol. 74, $\mathrm{N}^{\circ}$ 1, Nashville, Tennessee, American Economic Association.

Ferguson, Bruce (2006), "La gran importancia de las microfinanzas para vivienda", Microfinanzas para vivienda: una guía para la práctica, Franck Daphnis y Bruce Ferguson (eds.), San José, Hábitat para la Humanidad Internacional.

Ferguson, Bruce y Jesús Navarrete (2003), "New approaches to progressive housing in Latin America: A key to habitat programs and policy", Habitat International, vol. 27, $\mathrm{N}^{\circ} 2$.

Ferguson, Bruce y Peer Smets (2010), "Finance for incremental housing; current status and prospects for expansion", Habitat International, vol. $34, \mathrm{~N}^{\circ} 3$.
FONAVIS (Fondo Nacional de la Vivienda Social) (2010), Política de aplicación del Fondo Nacional de la Vivienda Social, Asunción, junio.

Friedman, Milton (1957), A Theory of the Consumption Function, Princeton, Princeton University Press.

Fruet Cardozo, Juan Vicente (2013), Nuevos modelos alternativos de financiamiento para el Paraguay, Asunción, A.G.R. Servicios Gráficos S.A., noviembre.

González Arrieta, Gerardo M. (2005), "El crédito hipotecario y el acceso a la vivienda para los hogares de menores ingresos en América Latina", Revista de la Cepal, vol. 86 (LC/G.2266-P), Santiago, abril.

Hammond, Allen y otros (2008), "The next 4 billion-the housing market", Global Urban Development, vol. 4, $\mathrm{N}^{\circ} 2$ [en línea] http://www.globalurban.org/GUDMag08Vol4Iss2/ HammondKramer.htm.

Kerekes, Carrie B. y Claudia R. Williamson (2008), "Unveiling De Soto's mystery: property rights, capital formation, and development", Journal of Institutional Economics, vol. 4, $\mathrm{N}^{\circ} 3$, Cambridge, Cambridge University Press.

Knapps, Francisco (2013), "Paraguay: déficit habitacional es de 1.200.000” [en línea] http://ea.com.py/v2/paraguay-deficithabitacional-es-de-1-200-000/.

Lorenz, Max Otto (1905), "Methods of measuring the concentration of wealth", Quarterly Publications of the American Statistical Association, vol. 9, $\mathrm{N}^{\circ}$ 70, Alexandria, American Statistical Association.

Ministerio de Hacienda (2013), "Se realiza hoy la última licitación de bonos del Tesoro en este año", 5 de diciembre [en línea] http:// www.hacienda.gov.py/web-hacienda/index.php?c=96\&n=5576.

Morton, William A. (1955), Housing Taxation, Madison, University of Wisconsin Press.

Muellbauer, John y Anthony Murphy (1997), "Booms and busts in the UK housing market", The Economic Journal, vol. 107, $\mathrm{N}^{\circ} 445$, Wiley.

Muth, Richard F. (1969), Cities and Housing, Chicago, Chicago University Press.

Páez, Katherine (2011), "Población, territorio y desarrollo sostenible: Notas de la reunión de expertos 16 y 17 de agosto de 2011", Documentos de Proyectos (LC/W.438), Santiago, Comisión Económica para América Latina y el Caribe (CEPAL) [en línea] http://repositorio.cepal.org/handle/11362/3933.

Poterba, James M. (1984), "Tax subsidies to owner-occupied housing: an asset-market approach", The Quarterly Journal of Economics, vol. 99, $\mathrm{N}^{\circ}$ 4, Oxford University Press, noviembre.

SENAVITat (Secretaría Nacional de la Vivienda y el Hábitat) (2012), Déficit habitacional en el Paraguay, Asunción.

(2010), Política de aplicación del Fondo Nacional de la Vivienda Social, junio.

Serageldin, Mona y John Driscoll (2000), Housing Microfinance Initiatives, Regional Summary: Asia, Latin America and SubSaharan Africa with Selected Case Studies, Center for Urban Development Studies, Harvard University Graduate School of Design, enero.

Smets, Peer (2006), "Small is beautiful, but big is often the practice: housing microfinance in discussion", Habitat International, vol. 30, $\mathrm{N}^{\circ} 3$, Amsterdam, Elsevier.

PNUD (Programa de las Naciones Unidas para el Desarrollo) (2010), El PNUD en acción. Informe anual 2010-2011, Nueva York.

Young, Cheryl (2007), "Housing microfinance: designing a product for the rural poor", Working Paper Series, $\mathrm{N}^{\circ} 19$, Andhra Pradesh, India, Institute for Financial Management and Research, noviembre. 